\title{
Effective implementation of SPC
}

\author{
Darja Noskievičová \\ VŠB-TU Ostrava \\ Czech Republic
}

\section{Introduction}

Statistical process control (SPC) is an approach to process control that has been widely used in any industrial or non-industrial fields.

SPC is based on so called Shewhart's conception of the process variability. This conception distinguishes variability caused by obviously effected common causes (process is considered to be statistically stable) from variability caused by abnormal assignable causes (process is considered not to be statistically stable).

The main goals of SPC is an identification of abnormal variability caused by assignable causes with the aim to

1. make the process stable,

2. minimize the process variability,

3. improve the process performance (see Fig. 1.).

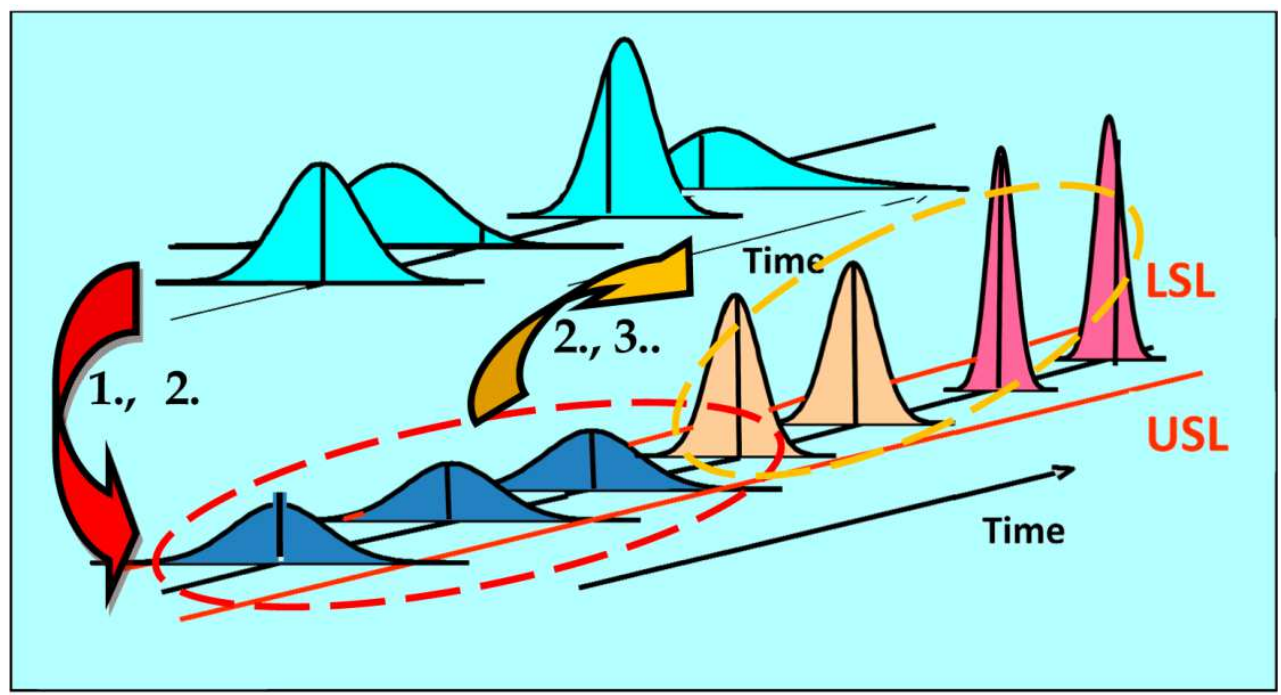

Fig. 1. Principle of SPC 
The main function is to "reduce variation in an output characteristic by signalizing the change of an undefined process input" (Dasgupta, 2003). Effective application of SPC is such complex application which leads to the reduction of the process variation, i.e. to the process improvement. Meeting this goal is affecting by many technical, statistical, methodical, social and economical factors. The rate of reaching this goal is proportional to the level of allowing for all groups of these factors during the SPC implementation and application and to the rate of integrating SPC into the overall business system of an organization.

But in practice there are many of the factors mentioned above that are not considered when implementing and applying SPC. It often led to ineffective and failure applications, demotivation of users and consequently de-evolution of SPC (Kelly \& Drury, 2002). This situation is strongly correlated to misunderstanding of the main goal of SPC.

The daily SPC utilization often predominantly consists of "merely plotting points in the control chart without any action whatsoever and at the end of the day filling it as an evidence of compliance to standardized procedures" (Dasgupta, 2003, p. 328).

The failure of SPC application may be often related to a wrong methodology. "In many cases people blindly believe that SPC is about plotting of control charts and sticking them on the walls for satisfying customers" (Antony \& Taner, 2003, p. 473). Kelly \& Drury (2002) state that "a long conflict between reaction to out-of control signals and ability to meet production schedules result in de-evolution of SPC in companies." They show that many people "find stopping the process because for identification and removing of assignable cause disturbing particularly in the situation when the quality characteristic lies in the specification."

Only process monitoring is not enough for meeting the main goal of SPC and SPC must be implemented in such a way to be able to offer correct and as quick as possible identification of assignable causes and realization of adequate corrective or improvement actions. SPC must be built as the problem-solving process. By the SPC design the general structure of the problem-solving process must be respected and the sequence of the subprocesses "Out-of control signal revelation - Root cause identification - Corrective or improvement action acceptance - verification of action" must be the axis of every SPC application. Other factors such as training, responsibility delegation etc. must support these activities.

In spite of the huge of literature on SPC regarding predominantly statistical factors (selection of control chart, construction of control chart, design of new types of control chart) there is little publications that offer practitioners complex methodology for implementing SPC as a problem -solving process. In general the SPC implementation issues are solved in several papers. Gordon et al. (1994) offer statistically supported analysis of factors associated with the successful implementation of SPC. They analyse factors such as top management commitment, training, responsibility for worker training, and involvement of workers. In connection with the last mentioned factor authors generally state that "quality issues are addressed best when personnel are fully engaged in the problem-solving process" (Gordon et al., 1994). But unfortunately they don't analyse SPC as the problem-solving process in deep and they permit about the defined SPC criterion's relationship to other factors there were not investigated in their study including the aptness of production decisions based on the SPC techniques and customer satisfaction. Some publications put the stress on the selected factors of the implementation of SPC - methodical aspects (Berger \& Hart, 1986) and organizational aspects (Gaafar \& Keats, 1992). The both types of factors more comprehensively are considered in the design of the framework for implementation of 
SPC in the next publication (Does et al., 1997). But issues such as interpretation of control chart, identification of assignable causes and selection of corrective or improvement actions are described only generally).

Other framework for the SPC implementation (Antony \& Taner, 2003) is the most complex of all. This conceptual framework covers steps such as construction of control charts and interpretation of control charts but this suggestion suffers from the same problems as the previous one - it offers only general well-known information about construction and interpretation of control charts recommendation to prepare and apply OCAP including. The only one proposal of the comprehensive framework for the SPC application with the special emphasis on the identification of assignable causes could be found in the paper of Dasgupta (Dasgupta, 2003). Author differs the activities linked to the identification of assignable cause according to the stages of the control charting defined in (Palm, 2000). In deep he discusses the problems and gives solutions for complex processes. A special attention he puts on the retrospective process analysis from the point of view of the identification of the assignable causes. But this proposal of the framework for the application of SPC suffers from several shortcomings. The applied three stage methodology is not complex - it doesn't cover capability analysis. It is not incorporated into the whole system of the factors influencing the effective SPC application. It doesn't respect all phases of the general problem-solving process. Very important phase of the selection of suitable solution (selection of the suitable corrective or improvement action) has been in this paper defined but has not been solved and the phase of the evaluation of the effectiveness of accepted corrective or improvement action has not been considered at all.

The goal of this paper is to

- define complex and effective application of SPC,

- systematically determine a comprehensive system of statistical, methodological, social and economical factors affecting the efficiency of the SPC application in relation to the steps of so called SPC cycle,

- define SPC as a total problem-solving process,

- define and describe four variants of practically applicable methodology of the SPC realization as a problem-solving process depending on the number of factors affecting the process variability and the degree of the process dynamics,

- show the practical example of the application of one of variants of the suggested methodology.

\section{Complex and effective application of SPC}

Complex application of SPC is such application that is realized in the frame of the following four phases:

I. Preparatory phase;

II. Phase of verification and ensuring the process statistical stability;

III. Phase of verification and ensuring the process capability;

IV. Phase of ongoing statistical process control.

In Table 1. there is a broad list of possible factors mentioned above that are identified in the frame of particular steps of the SPC cycle (see Fig. 2). 


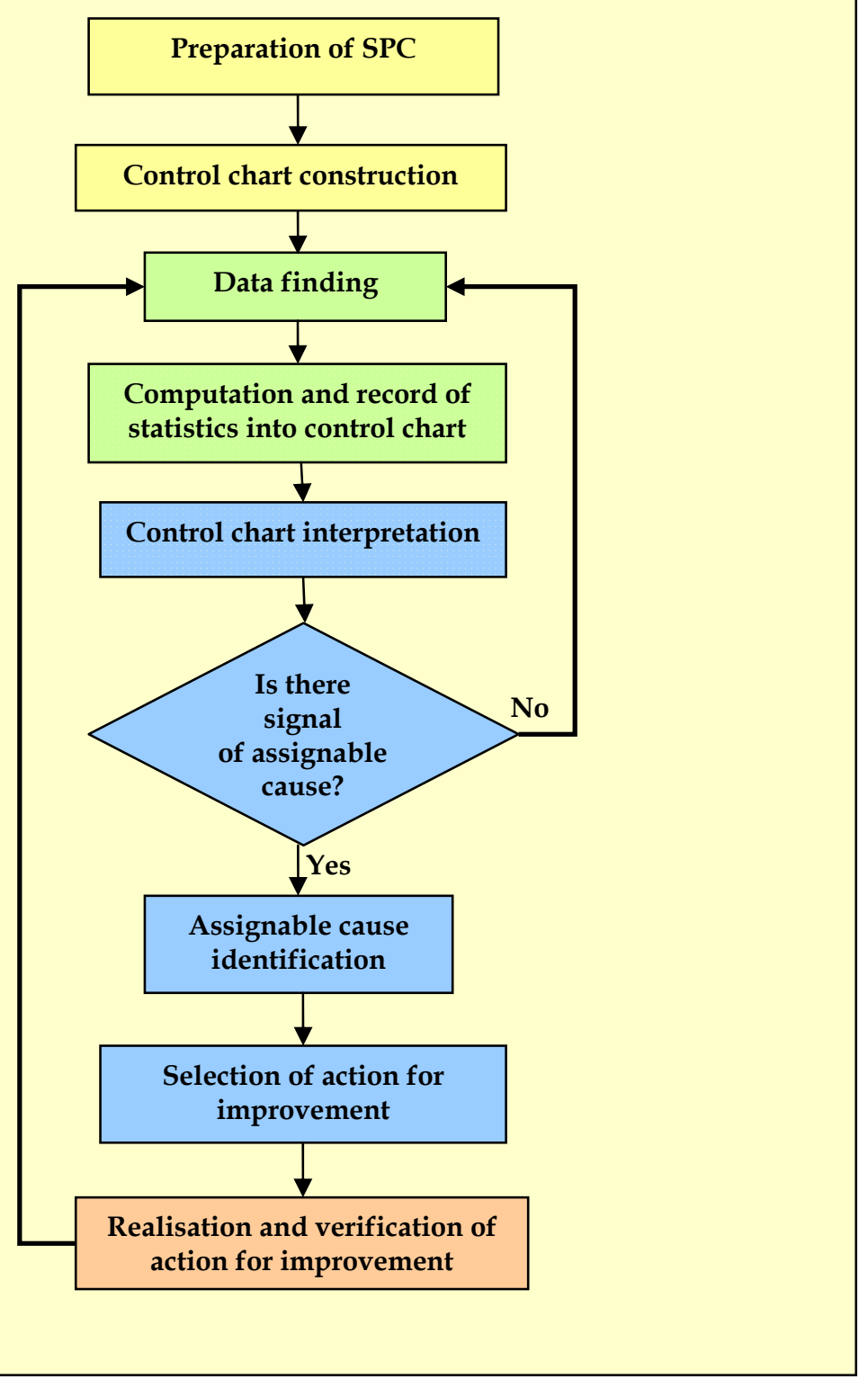

Fig. 2. SPC cycle 


\begin{tabular}{|c|c|}
\hline Step & Factor \\
\hline $\begin{array}{l}\text { Preparation } \\
\text { of SPC } \\
\text { implementation }\end{array}$ & 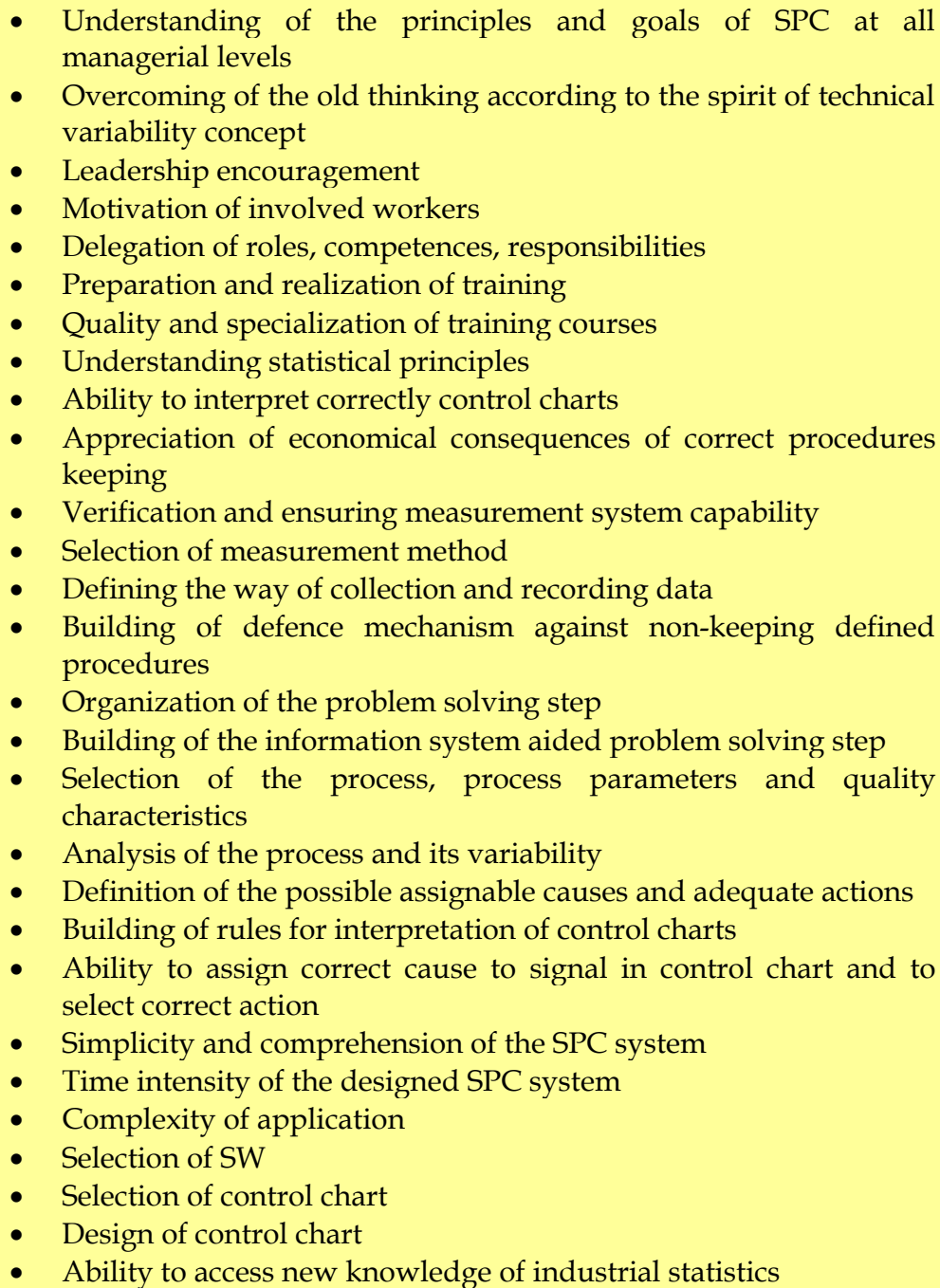 \\
\hline $\begin{array}{l}\text { Control chart } \\
\text { construction }\end{array}$ & $\begin{array}{l}\text { - } \text { Construction method } \\
\text { - Time intensity } \\
\text { - } \text { Mistake proofing }\end{array}$ \\
\hline Data collection & $\begin{array}{l}\text { - Observance of the defined procedure for data collection (control } \\
\text { interval, rational subgroups forming) } \\
\text { - Observance of the defined procedure for the data finding and } \\
\text { recording } \\
\text { - Mistake proofing }\end{array}$ \\
\hline
\end{tabular}

Table 1. Factors of the effective SPC implementation 
Step

Computation and record of statistics into control chart

Control chart interpretation

Assignable
causes
identification

\section{Factor}

- Way of computation and statistics recording

- Complexity of statistics computation and recording

- Keeping the procedure for computations and recording

- Mistake proofing

- Rules existence

- Clear determination of competencies and responsibilities

- Ability to "read“ in control chart

- Skills of responsible workers

- Clear determination of competencies and responsibilities

- Existence of the system of recording and processing historical data concerned in the process variability causes

- Deep knowledge of the process variability and its causes

- Identification speed

- Existence of the system for decision making and problem solving support

- Motivation for making identification

- Costs of identification

- Ability to assign cause to signal of nonstability in control chart

- Leadership encouragement

- Time sources

- Communication abilities

- Experience

\begin{tabular}{|c|c|}
\hline $\begin{array}{l}\text { Selection of } \\
\text { action for } \\
\text { improvement }\end{array}$ & $\begin{array}{l}\text { - } \text { Clear determination of competencies and responsibilities } \\
\text { - Knowledge in the process } \\
\text { - Database of causes and possible or accepted actions } \\
\text { - Costs of realization of particular actions } \\
\text { - Existence of information about efficiency of accepted actions } \\
\text { - Managerial encouragement } \\
\text { - Speed of realization of selected actions } \\
\text { - Realization of balancing costs and benefits of possible actions } \\
\text { - Experience }\end{array}$ \\
\hline $\begin{array}{l}\text { Realization } \\
\text { of action for } \\
\text { improvement }\end{array}$ & $\begin{array}{l}\text { - Clear determination of competencies and responsibilities } \\
\text { - System for evaluation of the accepted action impact and for the } \\
\text { results recording } \\
\text { - Resources for realization } \\
\text { - Experiences }\end{array}$ \\
\hline
\end{tabular}

Table 1. Factors of the effective SPC implementation - continuation

But in practice there are many of the factors mentioned above that are not considered when implementing SPC. It results from misunderstanding of the main goal of SPC.

Only process monitoring is no match for meeting this goal and SPC must be implemented in such a way to be able to offer correct and as quick as possible identification of assignable causes and realization of adequate actions for improvement. 


\section{SPC and problem-solving}

SPC must be built as a problem solving instrument. In the phase of the SPC design the general structure of the problem solving process must be respected and the sequence of the subprocesses "Out-of control signal revelation - Root cause identification - Corrective action acceptance - Verification of corrective action" must be the axis of the SPC application. This axis must be assured with many other actions to really operate.

\subsection{General structure of the problem solving process}

In this chapter basic subprocesses of properly operating problem solving process are defined. The structure of this process can be seen on the Fig. 3 .

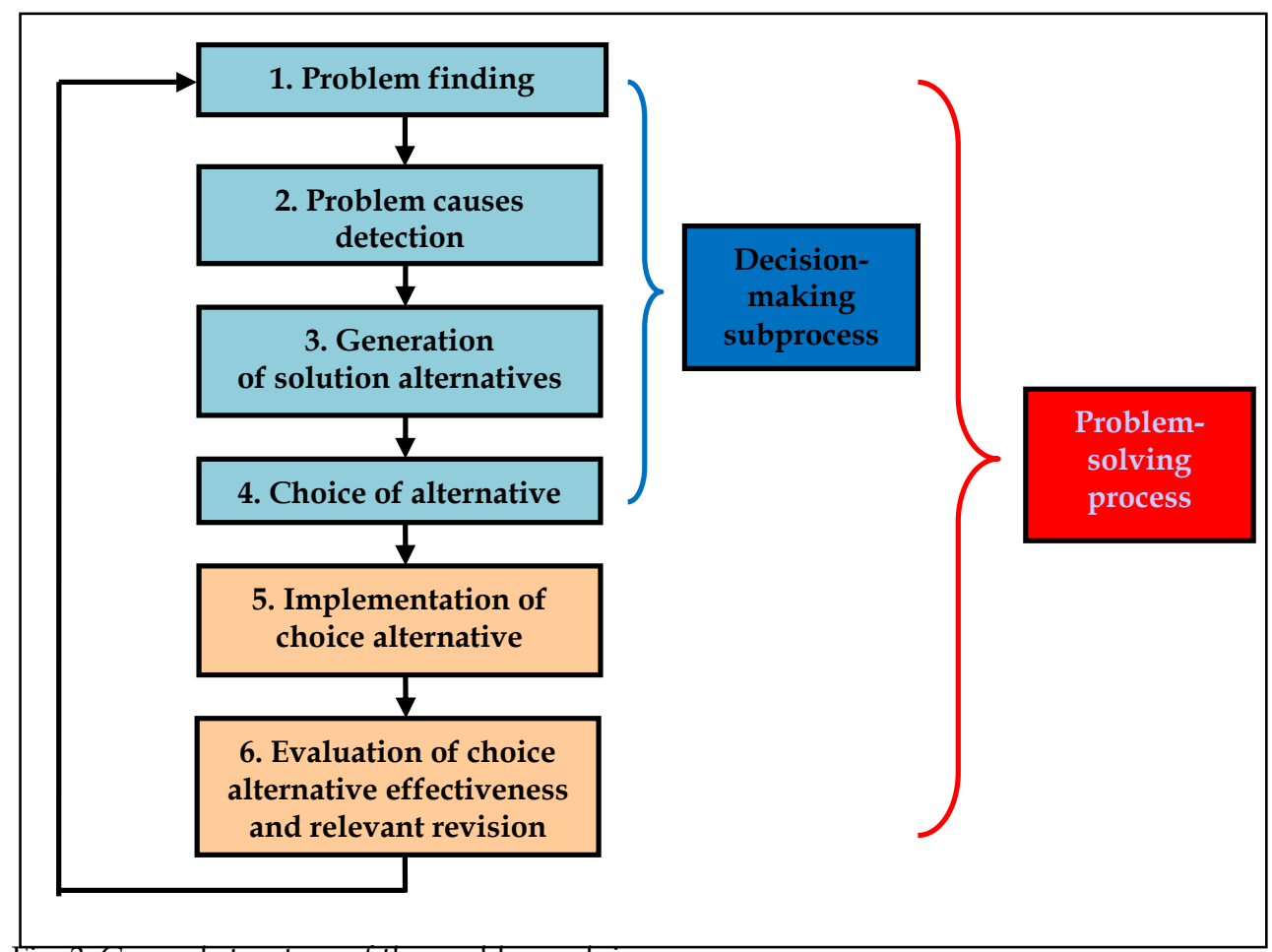

Fig. 3. General structure of the problem solving process

Decision-making is a part of wider problem-solving process and it covers activities such as identification, defining and diagnosis of problem, identification of the problem causes, solving alternatives generation, then evaluation and choice of alternative which best meets preset criteria. The decision-making subprocess is followed with the implementation of the choice alternative. The monitoring and evaluation of the choice alternative effectiveness altogether with relevant revision are activities forming the last subprocess.

The whole process is cyclic, the last step goes back to the first one. 


\subsection{SPC as a problem-solving process}

Respective problem-solving process in the frame of SPC follows the preparation of the SPC implementation and data collection and processing (see the relaxed SPC cycle on Fig. 4.). In the next paragraphs there is defined the content of separate subprocesses of decisionmaking process as a part of SPC (numbering of subprocesses is the same as it was used in the previous charter).

\section{Problem finding subprocess}

In the frame of SPC this subprocess covers activities connected with the control chart analysis on the basis of diagnostic rules defined during the preparatory phase (points out of control limits, nonrandom patterns). One or more points out of control limits or presence of some nonrandom pattern inside limits makes self problem.

\section{Subprocess of the problem cause identification}

The next subprocess of the problem-solving process in the frame of SPC there is an identification of the root problem cause which have lead to the signal of the process nonstability in the control chart. This subprocess has a fundamental influence on the effectiveness of SPC and practical experience shows that its undervaluation can result in failing of the whole SPC implementation. Without effective realization of this subprocess the main goal of SPC (reduction of variability and improvement of the process) cannot be met. It needs many supportive activities and creation of quality information system using both simple methods and instruments (Ishikawa diagram, Pareto diagram, check lists, data stratification in control charts) and more complex methods in a case of a complex process (regression analysis, DOE, discriminant analysis, fuzzy logic (Hou \& Tong, 2008), expert systems.

\section{Subprocess of the solution alternatives generation}

In the frame of this subprocess there is needed to define all possible activities that can result in the elimination of the identified assignable cause or at least to its restriction. This step also needs quality database containing list of all possible assignable causes with assigned possible corrective actions. In literature can be found recommendation to create so called OCAP, or properly structured expert system.

\section{Subprocess of the solution choice}

In SPC it covers activities such as choice and design of the corrective action or action for improvement. Realization of this subprocess can also be more effective via creating and using suitable database. The base of it could be formed by the list of already accepted corrective or improvement actions with relevant identification information. This information can be treated using Pareto analysis for particular assignable cause. A staff member responsible for choice of suitable corrective or improvement action could read from this analysis that actions were accepted most frequently. This information could speed up his decision. The speed of this process is another basic criterion that determines the effectiveness of the SPC implementation. In more complex cases this data base could be a part of the mentioned expert system. 


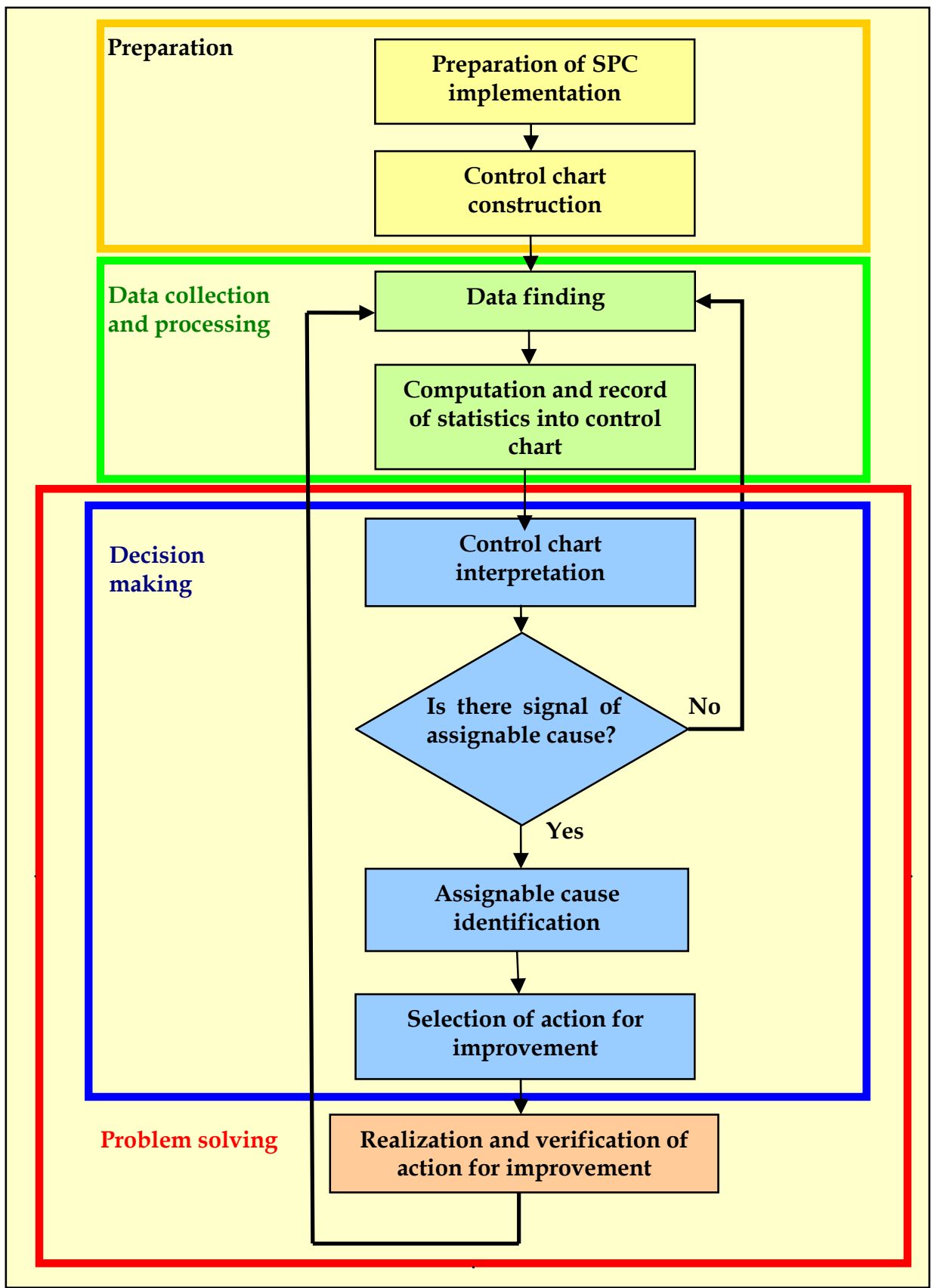

Fig. 4. Relaxed SPC cycle 


\section{Implementation of the choice solution}

This subsystem represents true intervention into the process that could result in the real reduction of the process variability and its improvement. It can represent organizational, technological, technical and other solutions.

\section{Evaluation of corrective or improvement action and eventual revision}

Monitoring and evaluation of the effectiveness of accepted corrective or improvement actions must be integral part of the problem-solving process. Obtained information can help to speed up the future decision-making in the frame of the 4 th subprocess. The effectiveness can be evaluated using the indicator of the corrective or improvement action effectiveness which expresses how many \% of such realized actions resulted in the process variability reduction. When $\mathrm{E}(\mathrm{RA})_{\mathrm{ij}}$ is the $\mathrm{i}^{\text {th }}$ kind of action accepted for the solving of the $\mathrm{j}^{\text {th }}$ cause then its efficiency can be determined using the next formula:

where

$$
E(R A)_{i j}=R A_{i j}(e) / R A_{i j}(c) .100
$$

$\mathrm{RA}_{\mathrm{ij}}(\mathrm{c}) \ldots$ is the whole number of the $\mathrm{i}^{\text {th }}$ kind of corrective action realized to solve $\mathrm{j}^{\text {th }}$ cause,

$\mathrm{RA}_{\mathrm{ij}}(\mathrm{e}) \ldots$ is a number of realized actions of $\mathrm{i}^{\text {th }}$ kind resulting in the process variability reduction, $\mathrm{i}=1,2, \ldots, \mathrm{m}$,

$\mathrm{m} . . . \ldots .$. is a number of various kinds of actions accepted for the solution of $j^{\text {th }}$ cause, $\mathrm{j}=1,2, \ldots, \mathrm{n}$,

n.........is a number of various kinds of causes so far identified in connection with specific symptom of nonstability.

This information is also important from the point of view of selection of the correct action because so far most often realized action need not to be the most effective one. For this reason when applying Pareto diagram for the analysis of the most often realized actions it should contain also indicator of efficiency of every kind of so far realized actions.

\subsection{Specificity of the problem-solving process in the frame of SPC}

The problem-solving process in the frame of SPC is characterized by some specificity that requires also specific access to its realization.

- Corrective or improvement actions must be realized as soon as possible after signal of working of assignable cause, given by the control chart.

- Many actions realize operators with limited time.

- The people influence cannot be excepted in full.

These specificity must be considered during the implementation of SPC.

\section{Methodology of realization of the problem-solving process in SPC}

Designed methodology is structured according to the number of factors (inputs) that have influence on the analyzed quality parameter of the product (output) and according to the rate of the process dynamics. Based on the combination of these two criteria there have been defined 4 variants of the methodology (see Table 2.).

Because of the necessity to react to the signal of working of assignable cause, given by the control chart as soon as possible a lot of information for decision-making must be taken already in the preparatory phase. The designed methodology contains only activities needed for the realization of the problem-solving process. 


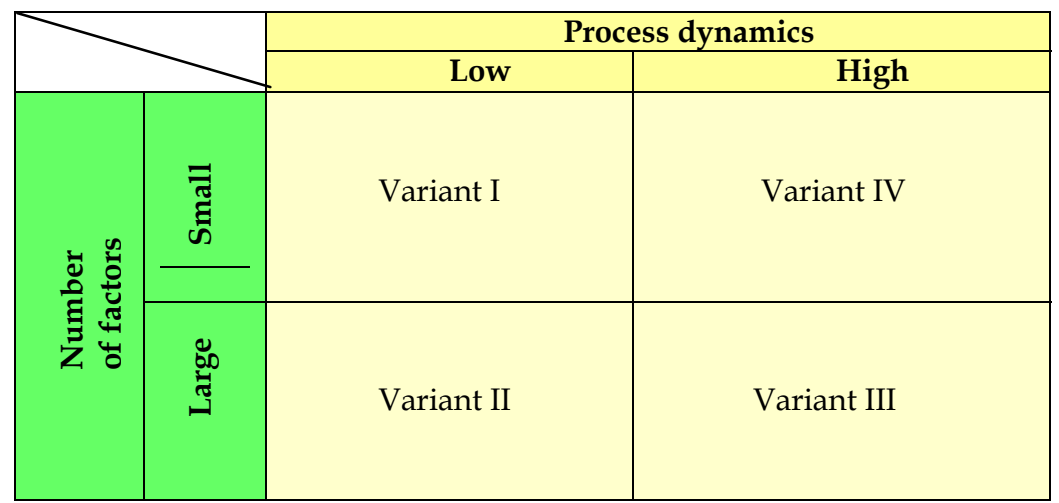

Table 2. Basic variants of the methodology

\subsection{Variant I}

Realization of the variant I is schematically visualized by the Fig. 5. During the preparatory activities it is necessary to create the check sheet for recording the values of the analysed quality characteristic and the document called Accompanying process sheet. It obviously consists of a part with the specifications of the process and product, specification of control chart (type of control chart, sample size, control interval) and a part for records of values of a quality characteristic including specification of time of data collection and a sign of person responsible for data recording. In a case of hand-made control charts this check sheet is represented by so called Control card even containing a part with control charts.

The Accompanying process sheet is a document where it is necessary to record every intervention into the process (maintenance activities, machine setting), its changes (change of operator, material batch change) or identified assignable causes including datum and sign of a responsible employee. This document could be carried out as a separate one but it could be a part of the control chart mentioned above.

During preparation of the implementation of SPC it is necessary to decide about rules for assessment of nonstabilities of the process. It is essential to clearly declare and document that is considered to be a signal of the process nonstability (if only points out of control limits or some nonrandom patterns, too. In the second case it is necessary to define that nonrandom patterns will be applied).

Another task which must be realized before implementation of SPC and which is tightly connected with SPC as a problem-solving instrument, is an assignment of potential nonstability causes that have an influence on the variability of the analyzed quality characteristic of product. Very simple method could be applied to such task - Ishikawa diagram. 


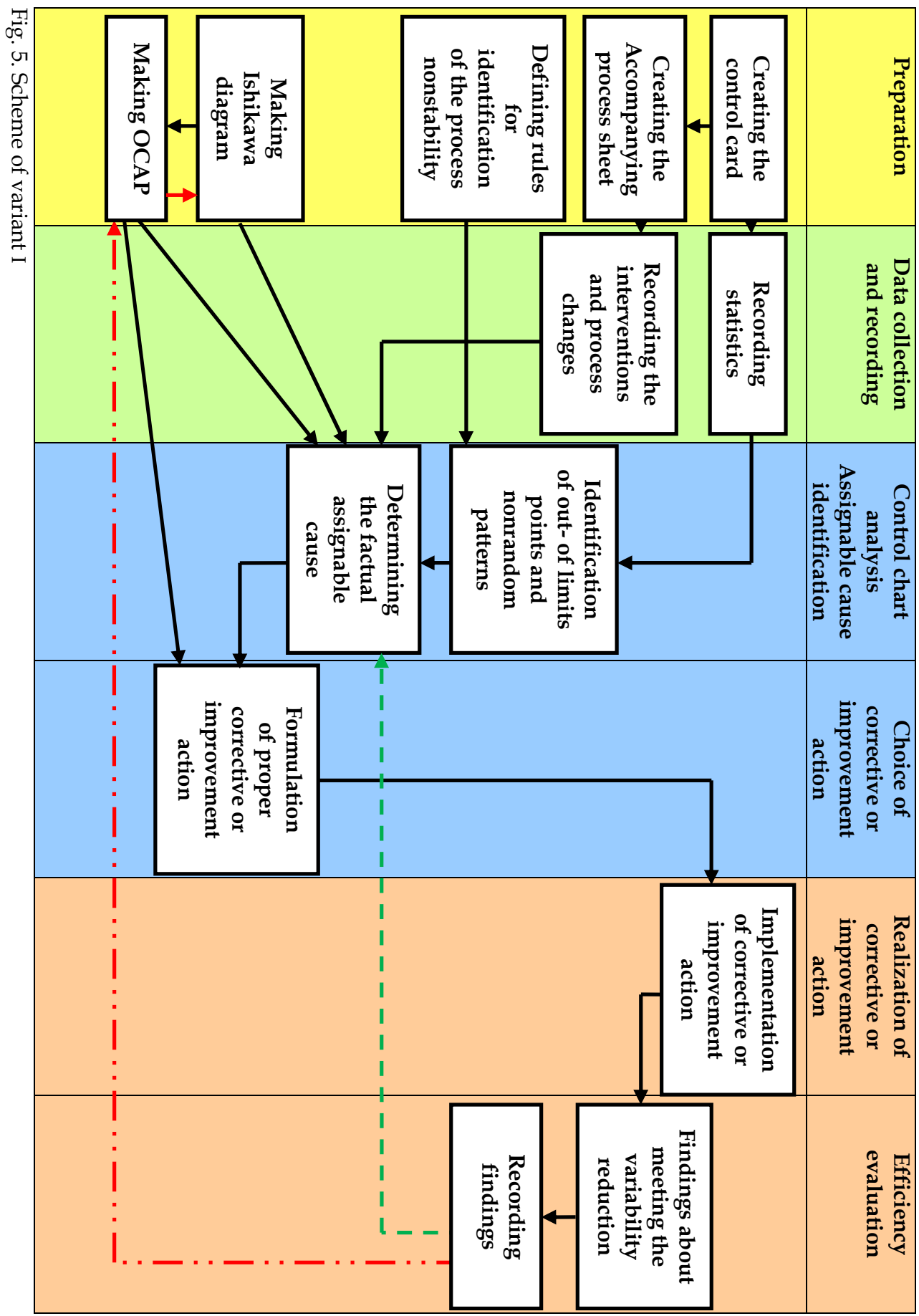


As in variant I small number of factors influencing watched quality characteristic is considered all these defined cause of variability are considered during the next analysis. These causes are assigned to defined signals of nonstability and to the particular causes are assigned corrective or improvement actions. This list is called OCAP (Out-of control action plan). From the point of view of the main goal of SPC it represents one of the most important information sources.

After recording values to control chart and records to Accompanying process sheet (eventually after translating data into SW) it is necessary to make an interpretation of control charts. That means to find signals of nonstability using predefined rules. When signal has been identified it is necessary to determine the factual assignable cause using information from Ishikawa diagram or OCAP.

Through the information in OCAP and eventually through records of the efficiency of accepted corrective or improvement actions there is then selected the most suitable corrective or improvement action which must be realized as soon as possible.

On the base of the subsequent data collection and evaluation of the process stability using control chart it is necessary to judge the stabilization of the process and the reduction of the process variability. Results must be recorded. When it has not resulted in the positive results it is necessary to repeat the cause analysis and assignment of the corrective action or to make the new Ishikawa diagram and update OCAP.

\subsection{Variant II}

The second variant of the methodology for the realization of the problem-solving process in the frame of SPC (Fig. 6.) has been designed for the processes with low dynamics but with larger number factors influencing the analyzed quality characteristics. It evokes additional activities within the preparatory phase. From all factors (causes) defined in Ishikawa diagram the most probable causes must be selected by score and then the most important causes must be chosen using for instance Pareto analysis. Some quantitative indicator then should be assign to every important cause. The check sheet for recording values of these indicators should be then designed to be possible to explicitly assign these values to rational subgroups of the analyzed quality characteristic values. In OCAP corrective or improvement actions will be bound to these indicators. It means that both values of controlled quality characteristic and values of indicators mentioned above must be collected and recorded. When control chart signalizes non-stability the analysis of these indicators must be realized in order to be able to identify particular cause of non-stability.

The next steps of the problem-solving process are the same as in variant I except the situation when the SPC has not resulted in the variability reduction. Then the selection and the analysis of the indicators could be repeated.

\subsection{Variant III}

The third variant of the methodology (Fig. 7.) represents expansion of the second one to the processes with both larger number of factors influencing controlled quality characteristic and large process dynamics. The preparatory steps must be added with the analysis of time leg in assignable causes treatment. 


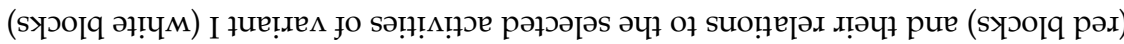

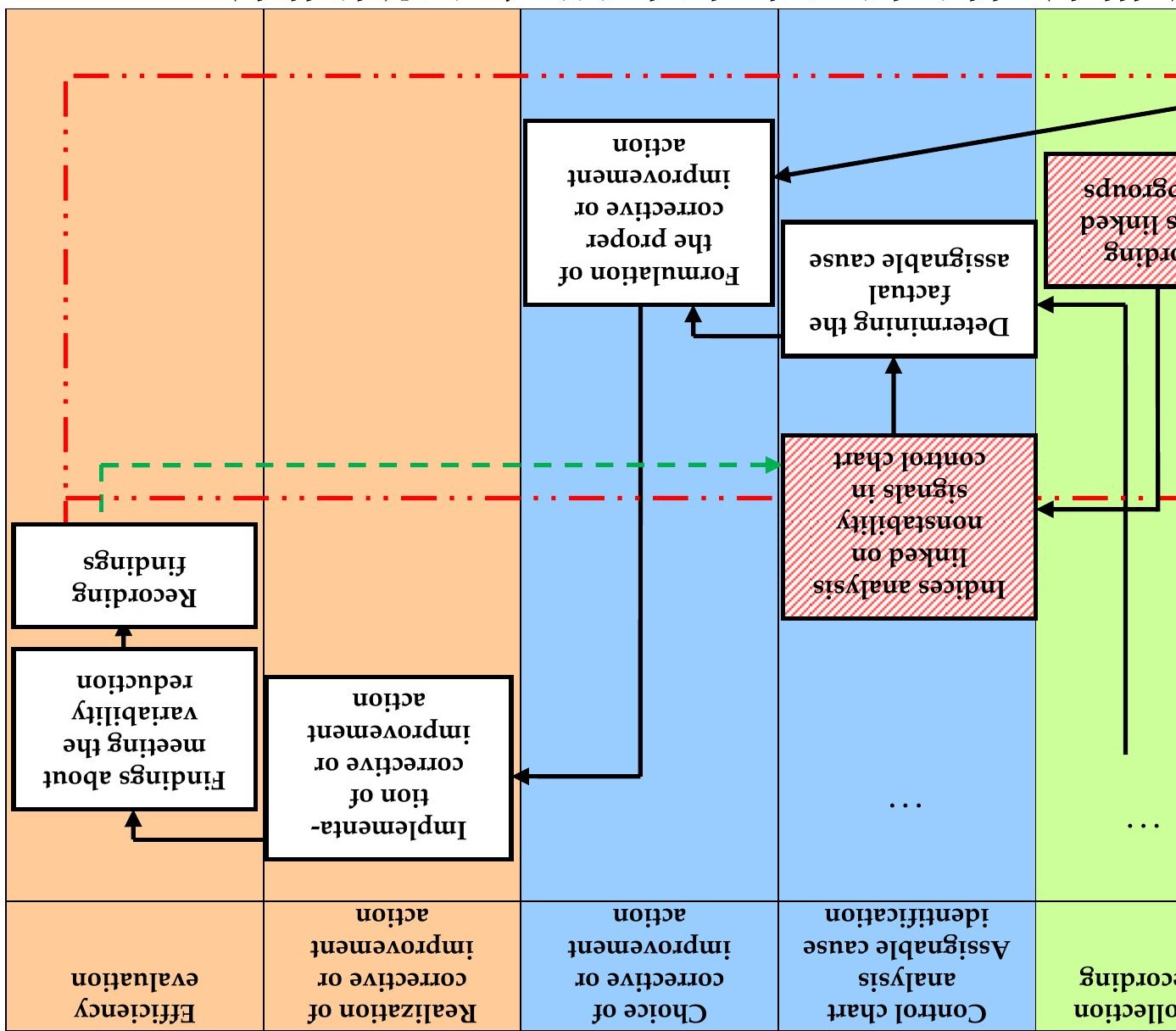




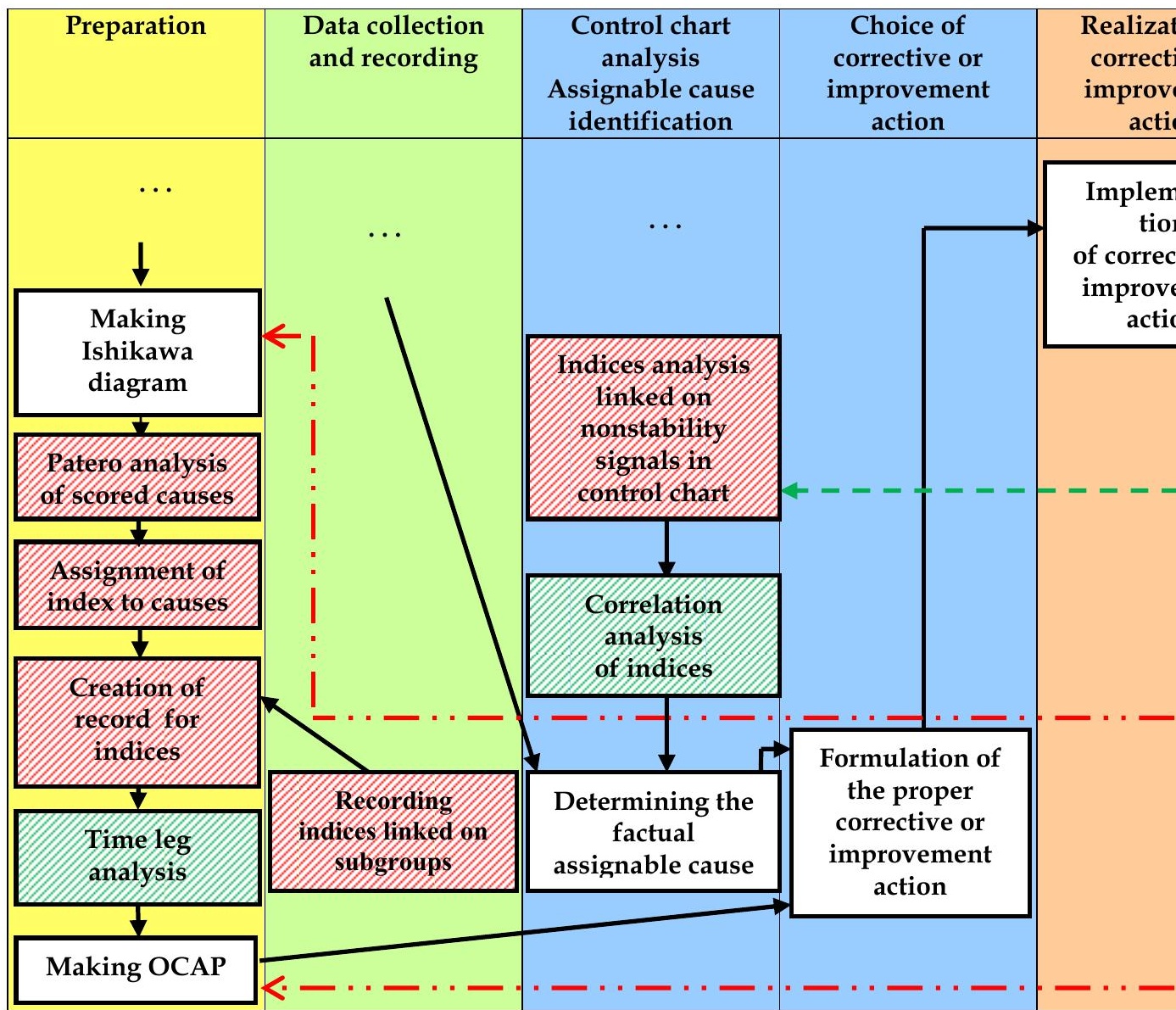

Fig. 7. Variant III: new activities (green blocks) and their relations to some activities of variant I (white bl 
Some of the causes can namely affect the controlled quality characteristic with time leg and it can evocate problems with assigning the indicator values to the values of sample statistics computed from the output quality characteristic values.

The analysis of the particular indicators in the frame of the assignable cause identification must be spread to (using regression and correlation analysis, DOE) in the situation when there exists important correlation between indicators and their joint could have an significant influence on the quality characteristics values.

The forth variant represents the combination of variants I and III.

\section{Proposal of expert system for problem-solving process in SPC}

As mentioned in chapter 3.2 good expert system can support problem-solving process in the frame of SPC and lead to effective and quick realization of its subprocesses. The proposal of expert system for SPC which is described in this chapter has two main parts: the block for the selection of the control chart and so called identification block.

\subsection{Block for selection of the control chart}

This block is the universal part of the expert system. The steps that must be realised to obtain the recommendation of the suitable control chart are described by the flow chart on the Fig. 8.

The expert system must contain tools for verification of all statistical pre-conditions about data. They are summarised in Table 3.

\begin{tabular}{|c|c|}
\hline Verified pre-condition & Tool for verification \\
\hline $\begin{array}{l}\text { Verification of correlation of more } \\
\text { characteristics }\end{array}$ & $\begin{array}{ll}\text { - } & \text { Test of significance of the correlation } \\
\text { coefficient } \\
\text { - }\end{array}$ \\
\hline Verification of data autocorrelation & $\begin{array}{ll}- & \text { Non-parametric tests for randomness } \\
- & \text { Test of significance of autocorrelation } \\
\text { coefficient }\end{array}$ \\
\hline Verification of data normality & $\begin{array}{ll}- & \text { Shapiro-Wilk test (for small data sets) } \\
- & \mathrm{X}^{2} \text { test (for large data sets) } \\
- & \text { Skewness test (large data sets) } \\
- & \text { Kurtosis test (large data sets) } \\
- & \text { Combined skewness and kurtosis test } \\
- & \text { Normal probability plot } \\
- & \text { Box-Whisker plot }\end{array}$ \\
\hline Verification of constant variance & - F-test \\
\hline Verification of the drift & - $\quad$ Test of significance of the gradient of line \\
\hline
\end{tabular}

Table 3. Tools for verification of preconditions about data 


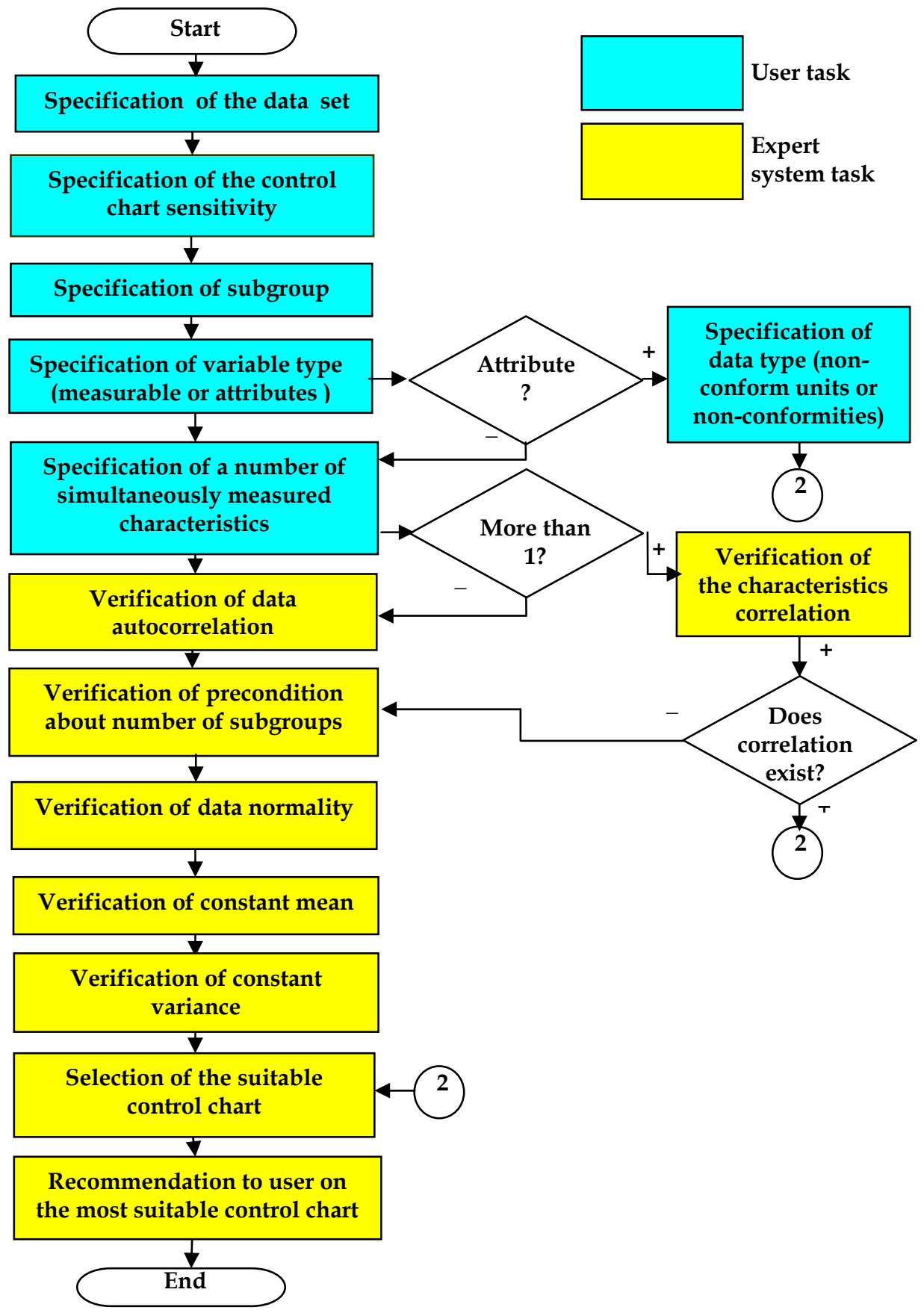

Fig. 8. Steps of block 1 of the proposed expert system for SPC 
Rules for the selection of suitable control chart that must be a part of the knowledge base are summarised in Table 4.

\begin{tabular}{|c|c|}
\hline Preconditions & Suitable control chart \\
\hline $\begin{array}{l}\text { Normally distributed data } \\
\text { One characteristic } \\
\text { Constant mean and variance } \\
\text { Non-correlated data } \\
\text { Suitable number of subgroups }(20-25) \\
\text { Low sensitivity of chart }\end{array}$ & $\begin{array}{l}\text { - Classical Shewhart control charts for } \\
\text { variables }\end{array}$ \\
\hline $\begin{array}{l}\text { Type of characteristic - attribute } \\
\text { - low sensitivity } \\
\text { - high sensitivity }\end{array}$ & $\begin{array}{l}\text { - Classical Shewhart control charts for } \\
\text { attributes } \\
\text { - } \quad \text { CUSUM charts for attributes }\end{array}$ \\
\hline $\begin{array}{l}\text { More than one characteristic } \\
\text { simultaneously measured on one unit } \\
\text { - correlated data } \\
\text { - non-correlated data }\end{array}$ & $\begin{array}{l}\text { - Hotelling chart } \\
\text { - Classical Shewhart control charts for } \\
\text { variables }\end{array}$ \\
\hline $\begin{array}{l}\text { Autocorrelated data } \\
\text { - positive autocorrelation } \\
\text { - all situations }\end{array}$ & $\begin{array}{l}\text { - Dynamic EWMA chart } \\
\text { - Shewhart control chart for individuals, } \\
\text { classical EWMA or CUSUM charts - } \\
\text { all applied to residuals from ARMA or } \\
\text { ARIMA models }\end{array}$ \\
\hline $\begin{array}{l}\text { Low number of subgroups } \\
\text { - consistent variance } \\
\text { - non-consistent variance }\end{array}$ & $\begin{array}{l}\text { - } \quad \text { Goal charts } \\
\text { - } \quad \text { Standardised charts }\end{array}$ \\
\hline $\begin{array}{l}\text { Non-normally distributed data } \\
\text { (for subgroup size less then 5) }\end{array}$ & $\begin{array}{l}\text { - Control chart with re-transformed } \\
\text { limits }\end{array}$ \\
\hline High sensitivity of chart & $\begin{array}{ll}- & \text { CUSUM chart } \\
\text { - } & \text { Classical EWMA chart } \\
\end{array}$ \\
\hline Non constant mean (drift) & $\begin{array}{ll}\text { - } & \text { Regression chart } \\
\text { - } & \text { Chart for residuals from regression } \\
\text { function }\end{array}$ \\
\hline
\end{tabular}

Table 4. Rules for selection of suitable control chart

\subsection{The identification block}

As compared to the block described above the second block of the proposed expert systemthe identification block is the part of the expert system that contains knowledge and experience of experts with the special process. This part is not universal but it will be differ from one process to other process. The goal of this block is to offer to user support for a quick identification of assignable cause of process variation and quick realisation of effective action. Steps that must be realised in the frame of this block are described using the flow chart in Fig. 9. We suppose that the initial information (specification of data set, subgroup size etc.) is shared with the first block for the selection of control chart. 


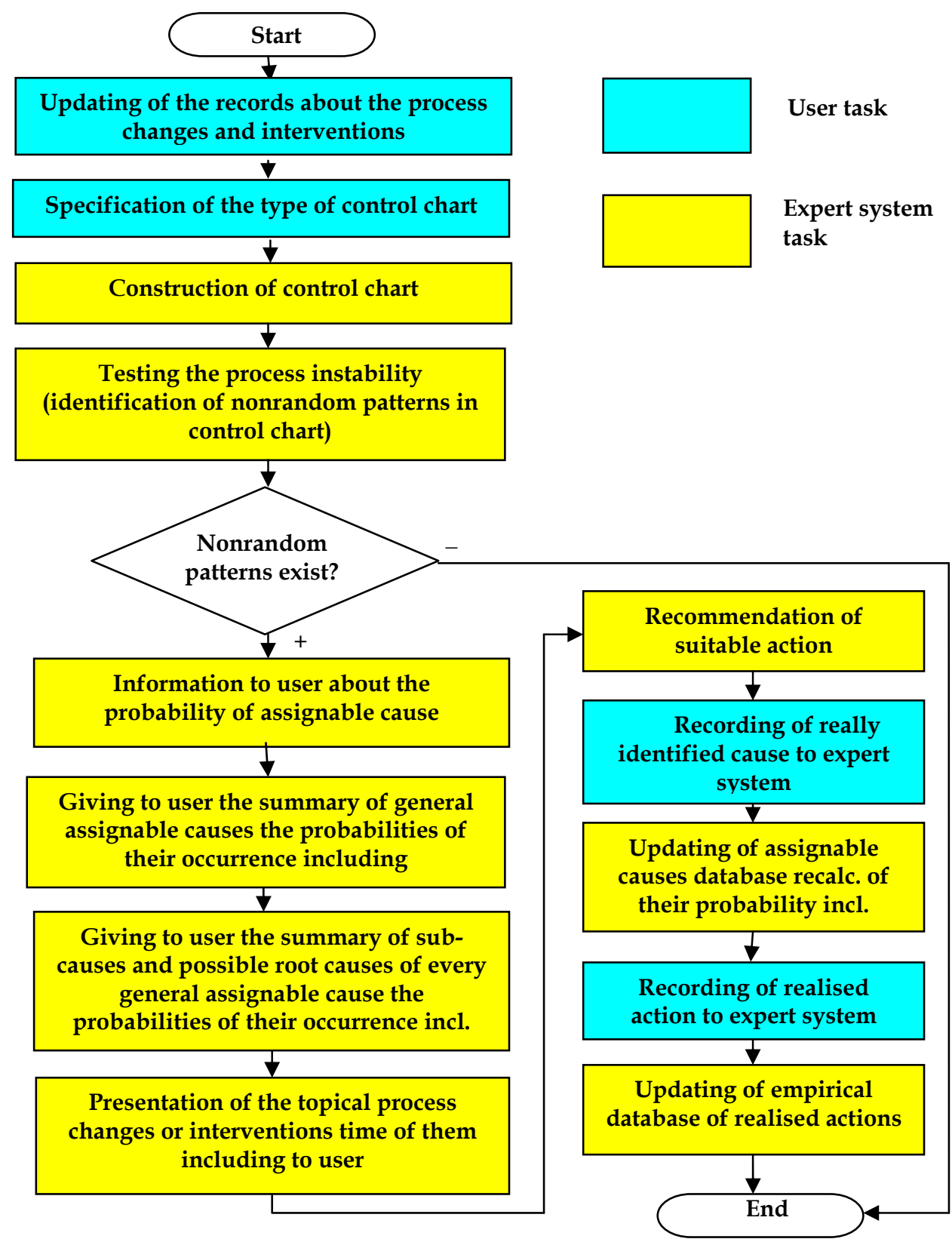

Fig. 9. Steps of block 2 of the proposed expert system for SPC 
The second block must contain algorithms for the construction and analysis of all control charts that are incorporated into the first block of the expert system. Some of them (classical Shewhart control charts, classical EWMA charts, CUSUM charts, Hotelling chart) are contained in many statistical software packages - some such statistical program could be a part of the operational system of the proposed expert system. But the algorithms for the construction and analysis of other control charts mentioned in Table 4. must be created and incorporated into the expert system.

Another part of the knowledge base for the second block of the proposed expert system are the tests of the process stability. It is suitable to divide this testing into two parts:

1. Testing in classical Shewhart control charts for sample mean and range

- for testing stability using these control charts the expert system should contain all developed tests of non-random patterns .

2. Testing of all other control charts incorporated into the expert system

- for all other charts we recommend to use only basic test (identification of the point behind the control limits) because of the lack of sufficient theoretical background.

Very important part of the knowledge base that the identification block needs for its operating is the part which contains special knowledge and expert experience with the controlled process:

a) Results of the team analysis of the process variation (using for instance Ishikawa chart, Pareto analysis) that give an initial summary of possible general and root assignable causes of the process variation and possible probabilities of their occurring.

b) Results of the history of the process - identified non-random patterns in the old control charts, records about all changes of the process, records of all really identified assignable causes, records of all realised actions.

\section{Practical application of the proposed methodology}

In this charter there are described selected steps of the preparatory phase of the application of statistical process control to the stamping of metal stampings for the automotive industry (Novosadová, 2010 ).

\subsection{Selection of the process, product and quality characteristic for SPC}

The company has decided to apply statistical process control to the stamping process which is the main production operation in the frame of the manufacturing of the product called spoiler holder (see Fig. 10.). This selection has been based on the customer request, production volume of the mentioned product which is the largest of all products produced in the company. The stamping process is realized on the transfer press Beutler $125 \mathrm{t}$.

The left and right front spoiler holder (Fig. 11. (a)) is the output of this process. It makes for mounting the front spoiler to the front fender on the left and on the right side. The basic requirements on the product characteristics are specified in drawing documentation. Specified dimensions and tolerances must be met, product mustn't have scratches, burrs and undesirable deformations. As a quality characteristic which values are used for statistical process control the shape deviation of the spoiler holder bill with tolerance $\pm 0,5$ $\mathrm{mm}$ was chosen (Fig. 11. (b)). This quality characteristic is measured using a digital drift meter. 


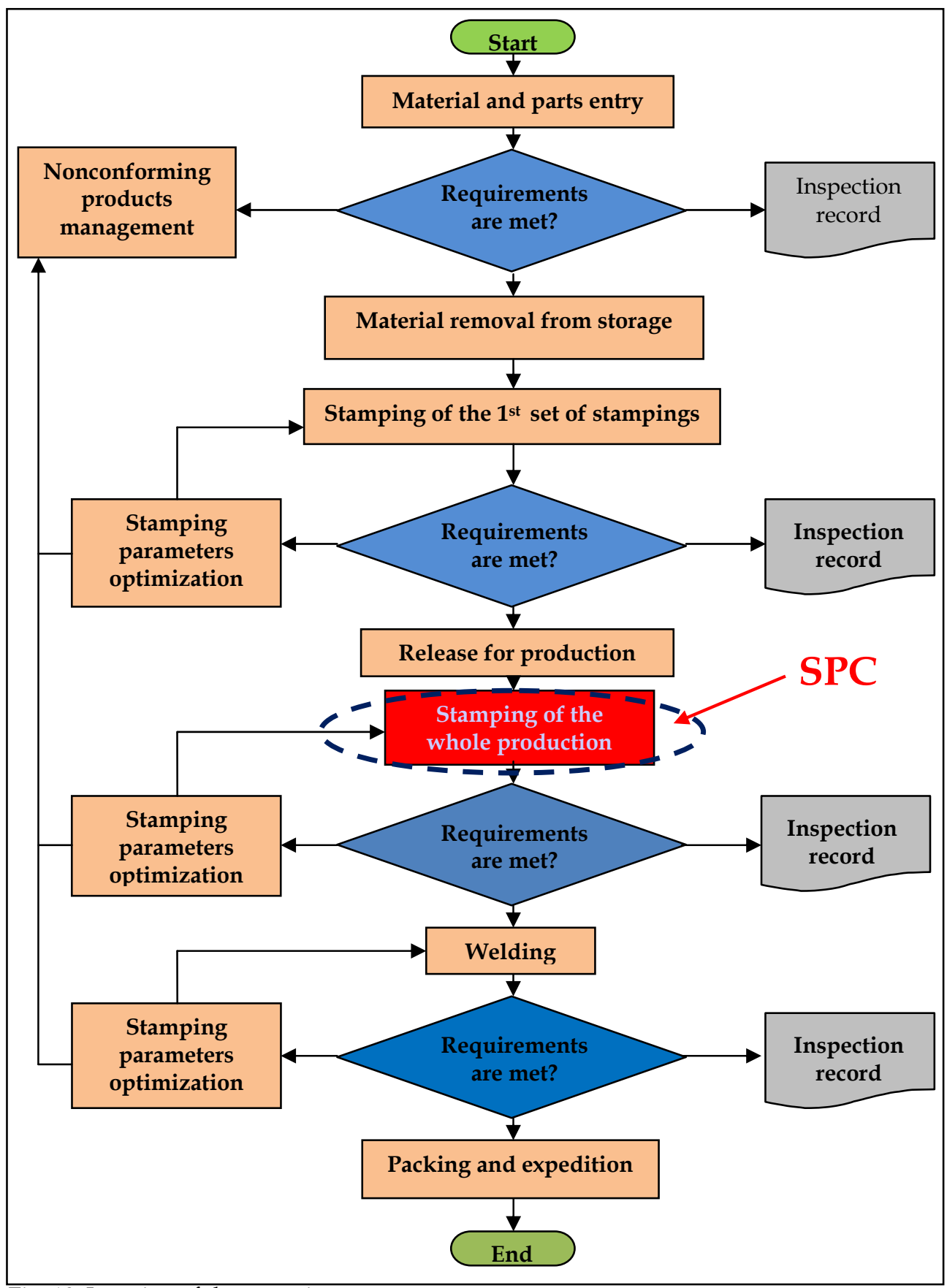

Fig. 10. Location of the stamping process 


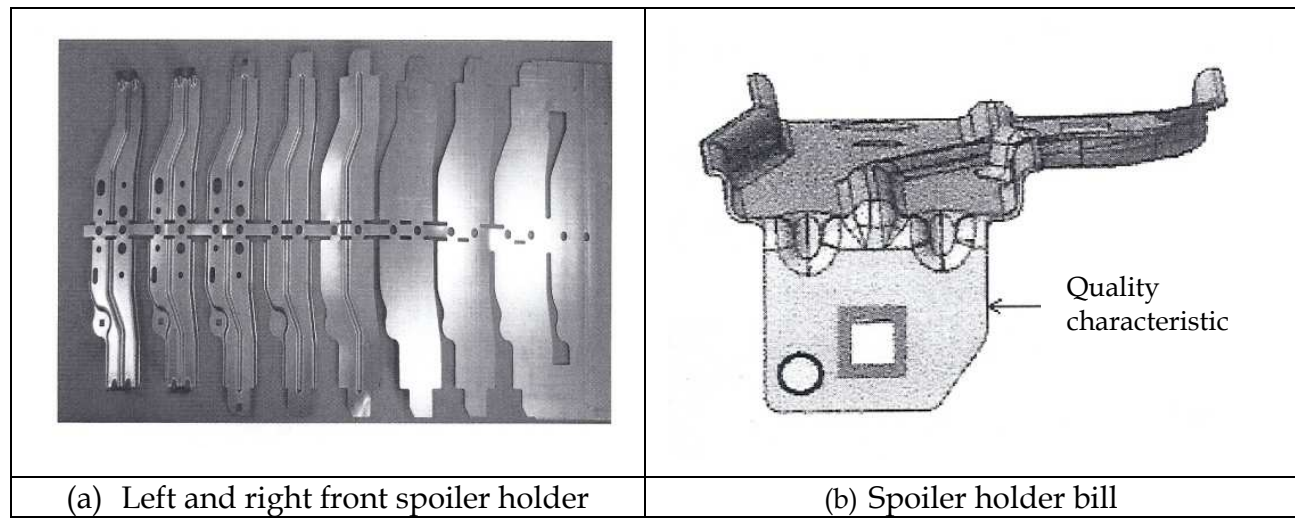

Fig. 11. Selected product (Novosadová, 2010)

\subsection{Measurement system analysis}

Complex measurement system analysis of the measurement of the shape deviation of the spoiler bill using a digital drift meter was realized by 3 operators 3 times on 10 randomly selected stampings. It resulted in GRR $\%<10 \%$. It confirmed the measurement system acceptability and credibility of the measured values.

\subsection{Analysis of possible causes of the spoiler bill shape deviation variability}

With the aim to set the most important potential causes of undesirable variability of the stamping process Ishikawa diagram was constructed as a result of the brainstorming. The team composed of the press operator, inspector, tool setter, toolmaker, quality manager and technical director defined as many as possible causes and then they scored in 5 rounds the most probable causes using 1-5 marks. Using Pareto analysis the most important causes were set and corrective or preventive actions were assigned (see Table 5.).

\begin{tabular}{|l|l|}
\hline \multicolumn{1}{|c|}{ Cause } & \multicolumn{1}{|c|}{ Action } \\
\hline Unsuitable position of force. & $\begin{array}{l}\text { Inspection of pinning of forces at every } \\
\text { preventive inspection. }\end{array}$ \\
\hline Wrong start-up of the presser. & $\begin{array}{l}\text { Regular inspection and record of the } \\
\text { press parameters in the same interval as } \\
\text { the values for the control chart, analysis } \\
\text { of these values along with analysis of the } \\
\text { control chart. }\end{array}$ \\
\hline Imprecise setting of the press high. & $\begin{array}{l}\text { Regular inspection and record of the } \\
\text { press parameters in the same interval as } \\
\text { the values for the control chart, analysis } \\
\text { of these values along with analysis of the } \\
\text { control chart. }\end{array}$ \\
\hline
\end{tabular}

Table 5. OCAP 


\subsection{Design of the system for data collection and record}

Five values of the selected quality characteristic (the shape deviation of the left and right spoiler bill) were proposed to be collected every 1 hour and recorded to the proposed control record. So called "Accompanying process sheet" for the record of every process change and interventions has been designed as a part of the record mentioned above (table 6.). It means that operator will sample 5 consecutive pieces of stampings of the right and left spoiler every hour. Immediately he will made an inspection of the spoiler bill using digital drift meter and measured values he will record into the suggested record sample time including. After every shift the operator will give the record to the quality operator who put the data in PC. In conjunction with the values mentioned above values of indexes that express cause start up of the press and setting of the press high will be measured and recorded into the suggested control record (see Table 7.) also every hour to be able to analyse these indexes altogether with control charts. The record will be linked to the control record of the quality characteristics used for statistical process control. The suggested way of the collection and data processing corresponds to the first variant of the designed methodology of the realization of statistical process control as a problem-solving process as the stamping is in principle not too dynamic process with the low number of factors influencing its variability.

Next verification of the data preconditions (normality, homogeneity, independence) was realized to be able to select the right control chart. After it the matrix of responsibility for all the actions that must be realized in the frame of statistical process control was put together.

\begin{tabular}{|l|r|r|r|}
\hline \multicolumn{3}{|c|}{ Accompanying process sheet } \\
\hline Date/Hour & Operator & Sign & $\begin{array}{c}\text { Assignable cause/Process } \\
\text { change/Interventions }\end{array}$ \\
\hline & & & \\
\hline & & & \\
\hline
\end{tabular}

Table 6. Accompanying process sheet

\begin{tabular}{|c|c|c|c|c|c|c|}
\hline & \multicolumn{5}{|c|}{ Start up of the press } & $\begin{array}{l}\text { Equipment: } \\
\text { Beutler 125t }\end{array}$ \\
\hline & \multicolumn{3}{|c|}{$\begin{array}{l}\text { Part name: Spoiler } \\
\text { Part number: } \\
\text { Instrument number: }\end{array}$} & & & Op.: Stamping \\
\hline Subgroup/ & $\begin{array}{l}\text { Lifting } \\
\text { height }\end{array}$ & $\begin{array}{c}\text { Operational } \\
\text { instrument } \\
\text { height }\end{array}$ & $\begin{array}{l}\text { Loader } \\
\text { height }\end{array}$ & $\begin{array}{l}\text { Feed } \\
\text { length }\end{array}$ & $\begin{array}{c}\text { Stamping } \\
\text { force } \\
\text { left } \\
\end{array}$ & $\begin{array}{c}\text { Stamping } \\
\text { force } \\
\text { right } \\
\end{array}$ \\
\hline value & & & & & & \\
\hline 1 & & & & & & \\
\hline 2 & & & & & & \\
\hline 3 & & & & & & \\
\hline & & & & & & \\
\hline$\ldots$ & & & & & & \\
\hline
\end{tabular}

Table 7. Control record 


\section{Conclusion}

This paper shows the need to realize a problem-solving process as an axis of vital complex and effective SPC system. After defining the complex and effective SPC implementation and factors of its efficiency four variants of the methodology for realization of the problemsolving process in the frame of SPC were described. As a part of the proposal of the methodology mentioned above the design of the expert system for SPC was described. Variant II of the methodology was then shown on the practical example in condition of the stamping process.

In future research more detailed scenarios of the effective and complex SPC implementation for different productive and non-productive branches in the frame of the designed methodology will be developed using the results of the research of barriers and stimulators of the SPC implementation in companies in Czech Republic and verified in practice.

The work was realized within the solution of the Czech national research project CEZ MSM 6198910019 Reduction of $\mathrm{CO}_{2}$ Production - DECO ${ }_{x}$ Processes.

\section{References}

Antony, J. \& Taner, T. (2003). A conceptual framework for the effective implementation of statistical process control. Business Process Management Journal, Vol. 9, No. 4, pp. 473-389, ISSN 1463-7154

Berger, R. W. \& Hart, Th. H. (1986). Statistical process control: A guide for implementation, M. Dekker, ISBN 0824776259, New York, NY.

Dasgupta, T. (2003). Maximizing the effectiveness of control charts: A framework for reacting to out-of-control signals, Proceedings of Annual Quality Congress, Vol. 57, No. 0, pp. 327-337, Kansas City, MI, June, 2003, ASQ, Milwaukee

Does, R. J. et al. (1997). A framework for implementation of statistical process control. International Journal of Quality Sciences,Vol. 2, No. 3, pp. 181-198, ISSN 1359-8538

Gaafar, L. K. \& Keats, J. B.(1992). Statistical process control: a guide for implementation. International Journal of Quality and Reliability Management, Vol. 9, No. 4, pp. 9-20, ISSN 0265-671X

Gordon, M. E. et al. (1994). Factors associated with the success of the implementation of statistical process control. Journal of High Technology Management Research, Vol. 5, No. 1. pp. 101-121, ISSN 1047-8310

Hou, S. - Tong, S. (2008). Fuzzy Logic Based Assignable Causes Ranking System for Control Chart Abnormality Diagnosis. Proceedings of IEEE 2008 (FUZZ 2008), pp. 49 - 53, ISBN 978-1-4244-1818-3, Hong Kong, June 2008, IEEE, Los Alamitos.

Kelly, H. W. \& Drury, C G. (2002). Socio-technical Reasons for the De-Evolution of Statistical process Control. Quality Management Journal, Vol. 9, No. 1, pp. 8-22, ISSN 1068-6967

Novosadová, M. (2010). Preparation of the SPC introduction to the stamping process. Bachelor thesis, VŠB-TU Ostrava, 45 p. (in Czech)

Palm, A. C. (2000). Discussion on "Controversies and contradictions in statistical process control". Journal of Quality Technology, Vol. 32, No. 4, ISSN 0022-4065 


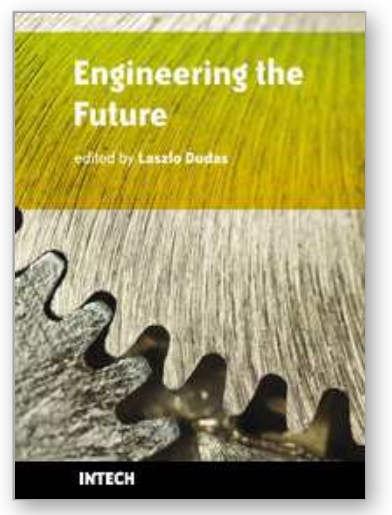

\author{
Engineering the Future \\ Edited by Laszlo Dudas
}

ISBN 978-953-307-210-4

Hard cover, 414 pages

Publisher Sciyo

Published online 02, November, 2010

Published in print edition November, 2010

This book pilots the reader into the future. The first three chapters introduce new materials and material processing methods. Then five chapters present innovative new design directions and solutions. The main section of the book contains ten chapters organized around problems and methods of manufacturing and technology, from cutting process optimisation through maintenance and control to the Digital Factory. The last two chapters deal with information and energy, as the foundations of a prospering economy.

\title{
How to reference
}

In order to correctly reference this scholarly work, feel free to copy and paste the following:

Darja Noskievicova (2010). Effective Implementation of Statistical Process Control, Engineering the Future, Laszlo Dudas (Ed.), ISBN: 978-953-307-210-4, InTech, Available from:

http://www.intechopen.com/books/engineering-the-future/effective-implementation-of-statistical-processcontrol-

\section{INTECH}

open science | open minds

\author{
InTech Europe \\ University Campus STeP Ri \\ Slavka Krautzeka 83/A \\ 51000 Rijeka, Croatia \\ Phone: +385 (51) 770447 \\ Fax: +385 (51) 686166 \\ www.intechopen.com
}

\author{
InTech China \\ Unit 405, Office Block, Hotel Equatorial Shanghai \\ No.65, Yan An Road (West), Shanghai, 200040, China \\ 中国上海市延安西路65号上海国际贵都大饭店办公楼 405 单元 \\ Phone: +86-21-62489820 \\ Fax: $+86-21-62489821$
}


(C) 2010 The Author(s). Licensee IntechOpen. This chapter is distributed under the terms of the Creative Commons Attribution-NonCommercialShareAlike-3.0 License, which permits use, distribution and reproduction for non-commercial purposes, provided the original is properly cited and derivative works building on this content are distributed under the same license. 